\title{
Data Envelopment Analysis (DEA) and Financial Ratios: A Pro-Stakeholders' View of Performance Measurement for Sustainable Value Creation of the Wind Energy
}

Submitted 17/01/20, 1st revision 14/02/20, 2nd revision 15/03/20, accepted 03/04/20

\author{
Panayiotis G. Curtis ${ }^{1}$, Michael Hanias ${ }^{2}$, \\ Eleftherios Kourtis ${ }^{3}$, Mixalis Kourtis ${ }^{4}$
}

\begin{abstract}
:
Purpose: The purpose of the paper is to explore business performance in a rather sensitive sector that equally combines economic, environmental and social dimensions. The paper investigates the efficiency of wind farm companies, in a framework of pursuing more diverse stakeholders' interests

Design/Methodology/Approach: Ratios and DEA approaches are combined to measure economic efficiency among the DMUs of a sample of wind farms, using data from their financial statements.

Findings: Productivity and effectiveness comprise the performance measured by the economic efficiency. We show that by choosing inputs and outputs that are closely related in forming an appropriate financial ratio, it helps to design and explain more fully the impact of a policy intervention aiming at improving economic efficiency. DEA supplements ratios to design, implement and assess a strategy of benchmarking towards bolstering performance, that favors a wider range of stakeholders.

Originality/Value: The study provides an in-depth insight into using Data Envelopment Analysis and financial ratios to study economic efficiency. The approach combines economic, social and environmental dimensions (indirectly) of performance, and the composite ratio Return on Total Assets (ROTA). The analysis caters the specific features of the sector renewable energy and their diverse stakeholders.
\end{abstract}

Keywords: DEA, financial ratios, performance measurement, stakeholders, corporate governance, wind farm energy.

JEL codes: C14, D21, D24, C61, M40.

Paper Type: Research study.

\footnotetext{
${ }^{1}$ Associate Professor, The National and Kapodistrian University of Athens, pkourtis@uoa.gr

${ }^{2}$ Associate Professor, International Hellenic University, mhanias@physics.ihu.gr

${ }^{3}$ M.Eng., LSE, M.Sc., Real Estate Economics and Finance, eleftherioskourtis@ gmail.com

${ }^{4}$ NTUA School of Electrical and Computer Engineering, mixaliscurtis@hotmail.com
} 


\section{Introduction}

The climate change is our paramount concern today. The US corporate leaders believe that "the access to sustainable, reliable, affordable energy is fundamental to U.S. national and economic security. Similarly, a clean and healthy environment is essential for economic prosperity now and in the long term" (The Business Roundtable, 2019). To meet the Paris Agreement's climate change goals, the International Renewable Energy Agency estimates around 26.000 billion of US\$ need to be invested in low-carbon power generation by 2050 (Ernst \& Young, 2019). Renewable sources of power and more specifically wind and solar farms "are seen as havens in coronavirus storm...attracting interest from investors hungry for lowrisk, stable-yield opportunities at a time of extraordinary market volatility" (The Wall Street Journal, March 31, 2020). The Energy Information Administration (USA) in its energy outlook for April 2020 reports, that "national electricity demand shrinking by $3 \%$ this year, but the renewables sector growing by $11 \%$ ", indicating tangibly the prospects for renewables.

China increased its wind power by $23.328 \mathrm{GW}$ in 2016 and USA by $8.203 \mathrm{GW}$ the same year (McKinsey, 2020). American wind farms invested \$11 billion in 2017. According to American Wind Energy Association (AWEA), wind capacity of 13,332 MW was under construction in 2018 and 15,336 MW in advanced development. It is representing a $34 \%$ increase annually (IEEFA, 2018).

Wind is considered among the cheapest form of new power generation in Europe (and not only) today. Electricity produced by wind turbine generates almost zero carbon footprint. The emissions displacement of wind power is $550 \mathrm{~g} \mathrm{CO} 2 \mathrm{eq} / \mathrm{kWh}$ for 2012 (Thomson et al., 2015). In 2018, the electricity generated from wind turbines, reduced carbon pollution by 200 million tons.

The sector attracted 26,7 and 19 billions of new investments in Europe in 2018 and 2019 correspondingly. The vision for the decade to 2030 for the European wind energy is to increase the capacity to $323 \mathrm{GW}$ compared to $208 \mathrm{GW}$ (expected by the end of 2020). It represents a 55,3\% increase. New investments to the tune of 239 billion euros are necessary to be attracted in the sector and 570,000 jobs will be created (Windeurope, 2019).

In Greece the capacity of the wind farming sector was $1.153 \mathrm{MW}$ in 2009 and reached 3.576 MW in 2019. It constitutes an increase of more than $210 \%$ in ten years. A capacity of 727,5 MW of which were installed in 2019. It represents an increase $25,4 \%$ compared to the end of 2018 .

The rapid increase in wind energy investment to boost capacity to energy production, is an essential step to reduce drastically carbon, towards a more sustainable future. Cost-competitiveness and agile scalability are prerequisites towards that development. The total benefits to society are not confined to the 
substitution of the largely imported fossil fuels. Wind generated energy will in addition improve air quality, health hazards emanating from pollution, that will also a) reduce health costs and b) increase energy security in Europe (Wind Energy, 2019). Wind generates $15 \%$ of the electricity in Europe today, cheaper than other forms and in an environmentally and social sustainable way (Windeurope, 2019).

To fulfil all these targets the wind energy sector, massive new capital investments are required. Towards exploring the existence of favorable preconditions for the sector in Greece, the efficiency of operation and the viability performance of a sample of wind farms operating already in the country will be examined. This exercise is expected to reveal also as a byproduct, possible strengths and weaknesses to be exploited by the appropriate strategy. The latter will help the sector to develop further and prosper, by fostering the cultivation of the appropriate business ecosystem and new investments in grid infrastructure. In exploring efficiency in a sample of companies of the wind farm sector, we will apply DEA analysis combined with financial ratios.

\section{Financial Ratios, Business Performance Measurement and DEA}

Financial ratios is a means of financial statement analysis. Ratios are derived from information obtained from the financial reports and are mechanisms of exploring different aspects of the economic wellbeing of an economic entity. Liquidity, activity, leverage, operating efficiency and profitability are the most common aspects of the financial health (Altman, 1968). Insights with respect the level performance of a company regarding the preceding aspects, are obtained by comparing the ratio of the company each year to the previous ones, or the average value of it for the industry it belongs to or the best performing competitor. Ratios are amenable to possible influence by the management intervention through manipulation, the size of a company, the age of an organization, the economy it operates etc., (Bernstein, 1988).

Efficiency measurement usually involves a comparison of actual performance achieved with an optimal one. Cost and revenue efficiencies are pivotal performance indicators. Either one though, reflects only one dimension and separately cannot portray the overall performance of an economic entity in a comprehensive fashion. A measure of profit efficiency is more suitable to reflect a more inclusive and integrated performance, since it encompasses both dimensions and it is more comprehensive. Profitability ratios of any sort (gross and net profit margins, return to equity, return to capital employed, ROE etc.) are usually applied to measure efficiency in business.

Along that reasoning, the profit margin was used to measure efficiency (and productivity) of operation of a fixed asset (as the energy sector) dominated industry (Fried et al., 2008). It is known that profit margins in turn, depends on operating revenues and costs. The size of revenues are related to prices charged and the 
utilization of available capacity. Any revenue inefficiency can be "technical," emanating from a failure to provide maximum service from the available resources, or "allocative," arising from the provision of wrong set of services, given their prices. Cost efficiency can also be "technical," if it is emanating from the degree of utilization of resources, or "allocative," arising from the fact that resources are not employed in line with their prevailing prices.

In the case of wind farm energy production, we are also dealing with fixed assets dominated balance sheets, that in addition doesn't have any other substantial operating costs, except some associated also with investments in total assets (ie depreciation, insurance, maintenance, debt financing etc). It is estimated that the main input in wind energy farms is the upfront costs, related fixed assets investments such as wind turbines, foundations, electrical equipment and grid connection. All of them represent approximately $75-80 \%$ of the total cost of energy. At the same time, their operation costs are very small compared to fossil fuel based technologies. Fuel cost doesn't exist and labor operating expenses are rather relatively insignificant. So, the crucial factors to efficiency analysis of wind-energy are costs that are related closely to the scale fixed investment and its financing. Pertinent works are the one that evaluates capital and operating cost efficiency of offshore wind farms (Ederer, 2015) or a ustainable site selection for offshore wind farms (Vagiona et al., 2018). Both examine the viability of the offshore wind farms with emphasis (among other things) in the capital cost involved and its sources of financing.

Examining profitability with data drawn from financial reports, we take care of the allocative efficiency in revenues, since prices are determined by the state in a uniform manner and the service (electricity power) render by DMUs, can't be differentiated. Major operating expenses (labor, fuel etc) that are not attributed to fixed assets, do not exist. So financial data incorporate prices in revenues and costs. Thus the allocative efficiency is what is measured.

As far the performance measure we choose to examine, it refers to the elements that constitute the composite index that estimates efficiency in a broader aspect. It is in line with the nature of wind energy as a means to reduce emissions (by displacing fossil), to improve air quality (the health-associated costs) and bolster Europe's energy security by reducing reliance on fossil fuel imports according to WindEurope.

We consider the financial variables that emanate from the Return on Total Assets (ROTA) or return on total capital) ratio, as a crucial reflecting most of the important aspects of performance. ROTA estimates the benefits to total assets (capital) used, regardless, if it is equity or debt proportions. The rest categories of ratios (liquidity, leverage etc) represent the means the management exploits to affect profitability (while keeping risks at an acceptable level), so that value, which is the outmost goal, be enhanced. 
The data used in the Data Envelopment Analysis were chosen so that inputs and outputs be connected in a very robust undisputable relationship. It is secured when data are inextricably linked to estimate ROTA. The latter is constructed by the capital turnover ratio, multiplied by EBIT margin of capital. ROTA in addition is considered a more broad measure of value creation by an economic entity, that serves more stakeholders than just the shareholders. It is a measure more properly tuned to the quest for more sustainable growth, proposed by the Business Roundtable 2019. We think its scope facilitates the development of wind farming electricity generation, at the time the planet tries to decrease environmental pollution at a sustainable level and promote inclusive growth.

ROTA is an indispensable measure used by public authorities mainly (as well as private ones in some cases), to allocate limited funds among the projects of a sector. The ROTA criterion is a more effective tool to maximize wealth creation for the stakeholders, compare to the Return on Equity (ROE), which take into consideration solely the degree of remuneration to shareholders. Our choice to select as inputs and outputs variables related to ROTA financial ratio, is in line with recent developments regarding the role of companies in the economy and society. A stakeholders approach is more appropriate for "a cohesive and sustainable world" (McKinseyDavos, 2020). It heralds a broader view of performance measurement, that "beacons an emerging shift away from the paradigm of shareholder capitalism", according to Brookings Institution (2020).

Capital (assets) invested is the one and foremost input, the efficient use of which determines decisively the viability of a wind farming DMU. The main expenses in operation represent the depreciation charges, financial costs in servicing the debt used (in financing fixed assets), insurance costs of facilities and possible cost of maintenance. All these items are closely associated to the scale of capital (assets) used. That is why capital (assets) invested is arguably the most crucial input factor. Total assets (or capital employed), revenues and EBIT are the building blocks of ROTA. Total assets is the main input. Revenues and EBIT are among the main outputs of its operation. ROTA is determined by EBIT margin to revenue, as well as to total assets turnover ratio by revenues. The formula defining it is:

ROTA $=$ EBIT $\div$ Total Assets

A more extended form of it, reveals the two individual ratios comprising ROTA, which are EBIT profit margin and total assets turnover ratio, according to formula:

ROTA $=$ EBIT profit margin $\mathrm{X}$ Total assets turnover

In order to calculate those two ratios, three variables that are necessary. Those are EBIT, Revenues and Total assets, according to the composite index:

ROTA $=$ EBIT $\div$ Revenues $\mathrm{X}$ Revenues $\div$ Total Assets 
We keep in mind that EBIT, Revenues and Total assets are closely intertwined to define EBIT profit margin and total assets turnover ratio and finally ROTA, which a broader and more comprehensive measure of efficiency.

The return on total assets (ROTA), is similar to the return on assets (ROA). The former though takes into consideration the return to all sources of capital employed including external financing, while the latter uses just net profits (the Du Pont formula). That is why ROTA is more comprehensive and of a wider scope than the ROA, which uses total assets also in the denominator, but nominator only net profits as ROE does (Courtis, 2003; Curtis et al., 2005). But net profits is the return to shareholders only.

Fixed assets are the most important attribute of capital intensive entities. The capital invested (fixed and current) is considered to be the base which determines the capacity of the entity to produce, attract and satisfy customers. The market share finally a corporation attains, depends on how readily and widely customers respond to the value proposition put forward by the organization at a given price. The scale of revenues produced it is known depends on the alignment of the product's (or service) characteristics to the tastes of the consumers and the prices offered.

The EBIT margin (with respect to revenues) reflects the overall efficiency of operations on annual basis. Total assets (fixed and current ones) is the total amount of capital that a company has utilized in order to generate revenues and all sorts of measured profits (including EBIT). It is tantamount to the sum of shareholders' equity and other liabilities.

Given that earnings (before/or after tax) is considered the return on equity capital and interest expenses is the remuneration to external capital (mainly debt and other liabilities), then the return to total (debt and equity) assets is equal to EBIT/ Total assets. EBIT also comprises taxes that are the revenues of government. Total capital turnover by revenues ratio (Revenues/Total assets or Total capital), reflects the effectiveness in the use of total assets. The scale of total assets used depends on the management's adeptness and the characteristics of the sector in which the entity operates. Some sectors require heavy fixed assets as a percentage of total capital (as in the case of wind farming electricity, hospitals, shipping, hotels, etc) (Courtis 2008). At the same time the total capital turnover ratio, expresses the contribution of a wind farm project in alleviating the burden of pollution, caused by the fossil fuel operating units withdrawn.

It is known that ROTA as a performance measurement tool is predominately used public authorities, banks etc that are interested in assessing the return on total capital used by an economic entity, regardless their source. That is why we prefer ROI instead of the most widely used ROE. It is a step towards examining financial performance in a more broad scope. ROTA ratio of a DMU above the average in a sector, denotes value creation and competitive advantage (Courtis, 2003; Curtis et 
al., 2008). The Business Roundtable (2019) consisting of the CEOs of major US corporations from all main sectors of the economy, promulgated a new Statement on the Purpose of a Corporation for corporate governance purposes. According to it "the purpose of a corporation is not just to create financial return to its shareholders, but to create benefits to all of its stakeholders (customers, employees, suppliers, communities, and shareholders) (Brookings Institute, 2020).

This development was verified and sealed also at Davos Manifesto 2020 which states that "the universal purpose of a company in the fourth industrial revolution is to serve clients, shareholders, workers and employees, as well as societies, and to harmonize the different interests of the stakeholders". Davos declaration invigorates the attempt for the establishment of a new dominant model that fosters the stakeholder capitalism in order to promote sustainability and inclusiveness in the existing market system. On the other hand $\mathrm{ROE}=$ Net Income $\div$ Shareholders' Equity, although it is a very useful profitability ratio, it concerns primarily the shareholders and has been criticized that it favors shortsighted outcomes in many cases (Curtis et al., 2005).

Next we are going to use the DEA model of measuring efficiency in an economic entity using input and outputs embedded in the previously described composite profitability ratio ROTA, which is of a wider perspective, accommodating better the interest of stakeholders and thus promoting sustainable development.

\section{Data Envelopment Analysis (DEA)}

The Data Envelopment Analysis (DEA) is a non-parametric comparative performance assessment tool, that can be applied to any group of entities that transform a variety of inputs to outputs, and doesn't have to specify in advance the type of relationship among them (Coelli, 1996). DEA allows comparisons in case of multiple inputs and outputs. Represent a linear programming based technique for measuring the relative performance of organizational units. The technique was introduced initially by Charnes et al. (1978) to measure the efficiency of input conversion into outputs. A measure of firm efficiency proposed by Farrell (1957) who defined the technical efficiency as the ability to obtain maximum output from a given set of inputs. Efficiency, measures how effectively inputs are transformed to specific outputs. The administration of efficiency contributes to the management's role to gain competitiveness, profitability and long term viability in a wider possible sense .

A Decision Making Unit (DMU) is any entity that exploits inputs to produce any form of output. Relative Technical Efficiency is the "ability of the DMU to obtain output, from a given set of inputs.

$$
\text { efficiency }=\frac{\text { output }}{\text { input }}
$$


It is an index of total outputs produced, divided by the total input used for that purpose. The efficiency score of each unit is expressed compared to the optimal performance of DMUs that excel in the group of reference that is under scrutiny. It is a relative measure compared to the one of the peer units and not an absolute one, that cannot be improved further (even for the so called efficient units). It is merely the champion in performance among the members of the group measured.

The resulting efficiency scores lie between zero and one. DEA scores divide DMUs into two categories, the efficient and inefficient ones. Score one (1) gets the case (s) located on the frontier that is considered efficient and constitutes the base for comparison. Their position is characterized as Pareto optimal. The output can't change without a corresponding change in inputs. The inefficient DMUs are rated greater than zero, but lower than one (1). A DMU can improve efficiency through DEA benchmarking, the adoption of best practices and appropriate strategy to obtain a more suitable production scale.

Charnes et al. (1978) in their work (following Farrel's seminal contribution) assume that Constant Returns to Scale (CRS) prevail (a change in inputs leads to an exactly proportional change in output), and proposed a frontier that measures the overall efficiency. The isoquant describes the "technological set" to produce the certain amount of output. It is a model under the assumption that the DMUs are operating at an optimal scale. It can happen when perfect competition prevails and no constraints exist in the market.

The BCC model developed by Banker et al. (1984) refines further the previous model and discerns that the overall technical efficiency is consisting of two factors, a) the pure technical and b) the scale inefficiencies. So, it identifies also whether at the given scale of operation, increasing or decreasing returns to scale possibilities exist. If imperfections in the market do occur, it may not be possible for DMUs to reach an optimal size of operations. In that situation, which is not scarce, the BCC model is appropriate to tackle the issue of the DMUs' return to scale. The latter applies when a percentage change in inputs, doesn't lead to an equal (but greater or lower) change in output. In that case the scale of operation is crucial and discerns the pure technical efficiency. So, a DMUs must decide on how to improve of efficiency and choose the appropriate scale of operation to achieve that. So, the DEA CCR and BCC models are used to derive the technical, pure technical and scale efficiency. Having calculated CRS and VRS efficiency ratios, the Scale efficiency (SE) can be derived as a ratio:

\section{CRS/VRS $=$ SE}

CRS/VRS measures scale efficiency attributed to the DMU scale-size. The value of scale efficiency denotes whether a DMU is operating under increasing - decreasing or not (Avrikan, 2011). Its values range between 0 and 1 . When it is equal to 1 , the VRS and CRS are equal and the DMU is operating at the optimal scale size. In every 
other case we have scale inefficiency. The firm is said to be scale efficient if it operates on a scale that maximizes productivity. Besides the concept of technically efficient when a set of outputs are attained using the smallest possible amount of inputs, there is also the concept of allocative efficiency that measures the ability of a firm to apply the inputs at optimal proportions in accordance with their existing prices. When a DMU is at the same time technically and allocatively efficient, it is characterized as cost efficient (Coelli, 1996). It is the most integrated concept of efficiency from all the above, that contributes to value creation, if prices of the output are high enough to cover costs and reflect the genuine utility to consumers who pay for.

It is obvious that DEA is a tool that fosters benchmarking and best practices in the management process. Benchmark management provides organizations with the tangible means to comprehend the ultimate result of adopting best practices in order to bridge the gap of companies with the best performing actors in their sector. It enhances efficiency and improves wealth for all parties involved. Efficiency contributes to the improvement of allocation of the factors of production, and thus to the overall wealth and prosperity in the economy. Efficiently operating units are rewarded by attracting additional investments. DEA is widely used in almost any sector of economic activity (hospitals, banks, Hotels, ports, education, agriculture, fisheries, etc. A comprehensive and enlightened review of the literature regarding DEA applications in sustainability can be found in Zhou et al. (2018), who allege that "DEA is is a valuable tool of sustainability performance evaluation".

\section{DEA Application on Wind Farm Companies}

Wind farms is a vibrant subsector that needs to attract massive investments funds to achieve its targets in energy production in a sustainable fashion. We are examining the efficiency of a sample of twelve (12) wind farms operating in Greece. To accomplish that task, we have chosen to use Data Envelopment Analysis using one input and two output variables extracted from the financial statements of the economic entities involved. We maintain the view that the most appropriate criterion that determines the degree of efficiency in the specific sector, is the one measured by a more broad profitability ratio the return on investment (Smith, 1990). The latter has two constituencies, EBIT margin and capital-assets turnover as well as three variables defining them.

As input variable we use the capital invested that is equal to total assets, which a controllable factor by the management and the most crucial factor in determining the scale of operation (reflected in investment and revenues collected) and the most essential costs that "dictate" the results of operation. The invested capital is by far the main input factor in the sector that determines efficiency. Fixed assets that dominate balance sheets of wind farms (representing $80 \%$ of the total), are considered as less amenable to distortions and as factors that are used frequently to manipulation of income statements. It can't happen in our case especially, given that 
the actual revenues are emanating from long term contracts with the state owned public utility company DEH (that is exclusively distributing electricity power in the entire country).

Efficiency measurement and its subsequent boosting (through the use of best practices in management of operations), contributes to attracting more capital in the sector by mobilizing new equity and debt capital. Wind farms' rapport and suitability to the goals of environmental sustainability and social cohesion through regional development and employment creation in remote areas, invigorates further the tendency for more investments in the sector especially in areas with favorable wind conditions. That is why the wind farm sector was chosen for new investments as a means of power generation to combat climate change, since sizable economic outcomes to rural areas have been sometimes questionable so far. The financial data of a sample of twelve wind farms we chose to examine as inputs and outputs, are the ones related to ROTA and this choice is in line with recent developments regarding the role of companies in the economy and society. A stakeholder approach to management promotes a cohesive and sustainable world (McKinsey, 2020; Davos, 2020).

We are applying an input oriented DEA approach, which indicates that an inefficient unit is made efficient through the proportional reduction of its inputs, while its outputs proportions are held constant (Ederer, 2015). We initially use the CRS model, which assumes efficiency of the DMU is not affected by the scale of its operations. So scale becomes an irrelevant factor at this stage. The data used are related to the twelve (12) DMUs (wind farm entities) operating in Greece, that published audited financial statements related to the year 2018. We have chosen specific data, that are reflected in the Table 1.

Table 1. Input and outputs data (in thousands euros)

\begin{tabular}{c||c|c||c} 
& Input & Output 1 & Output 2 \\
\hline DMUs & Total Assets & Revenues & EBIT \\
\hline \hline & & & \\
DMU 1 & $121.391,0$ & $23.821,0$ & $10.655,0$ \\
\hline \hline DMU 2 & $45.875,0$ & $5.668,0$ & $3.291,0$ \\
\hline \hline DMU 3 & $25.797,0$ & $4.649,0$ & $1.885,0$ \\
\hline \hline DMU 4 & $10.517,0$ & $2.344,0$ & 897,0 \\
\hline \hline DMU 5 & $32.913,0$ & $5.683,0$ & $2.393,0$ \\
\hline \hline DMU 6 & $38.121,0$ & $7.654,0$ & $4.864,0$ \\
\hline \hline DMU 7 & $19.845,0$ & $3.052,0$ & $1.369,0$ \\
\hline \hline DMU 8 & $59.071,0$ & $10.293,0$ & $4.574,0$ \\
\hline \hline DMU 9 & $28.064,0$ & $2.928,0$ & $1.197,0$ \\
\hline \hline DMU 10 & $33.290,0$ & $3.921,0$ & $1.749,0$ \\
\hline
\end{tabular}


Data Envelopment Analysis (DEA) and Financial Ratios: A Pro-Stakeholders' View of

Performance Measurement for Sustainable Value Creation of the Wind Energy Sector 336

\begin{tabular}{|c|c|c|c|}
\hline DMU 11 & $34.327,0$ & $6.693,0$ & $3.701,0$ \\
\hline DMU 12 & $7.831,0$ & $1.744,0$ & $1.092,0$ \\
\hline
\end{tabular}

Source: Own calculations.

We consider the size of total assets as the most crucial input in the sector, which is characterized by fixed capital intensive DMUs. We appreciate it as the main pillar of the most elaborate concept of levelized cost of electricity (LCOE). It includes the installed capital costs and ongoing operating costs and other factors that uses the computerized National Energy Modeling System (NEMS) are applied by the Energy Information Administration (EIA) in USA to estimate the energy, economic, environmental, and security impacts of investments in different energy producing technologies (EIA, 2020). We believe that total assets is the sufficient input for our analysis.

Revenues are used as the No 1 output. It reflects how effectively assets are transformed to energy production (prices are predetermined by long term contracts). EBIT measures the efficiency of operation (compared to revenues achieved) and represents the output No 2. Revenue generation without viability (reflected in adequate EBIT), is incomplete. Also, viability without enough revenues coming from energy production (that replace also fossil fuel energy units) is not very attractive. It erodes its lasting precondition for any kind of profits which is adequate market share (which also exerts favorable social and environmental impacts). Revenues-energy production volume (market share) considered the necessary ingredient for the DMU to become viable in the long term.

Getting a first glimpse of data used, we observe that the average amount of capital invested per DMU of the sample, is 38,1 million euros. The average unit generates revenues are 6,5 mil and EBIT 3,2 mil (or 48,3\% of revenues). The average capital turnover ratio (Revenues / Capital) is equal to 17,2 \% only (well below the usual turnover in any other customary sector of the economy), which is an emphatic characteristic of the fixed capital intensive sectors hotels, shipping etc, (Courtis et al., 2008).

We must also take into consideration that the annual depreciation represents grossly a $5 \%$ of fixed capital, as well as the related financing, insurance, maintenance and repairs costs are associated with it and determine largely the results of the income statement. So, these sectors are more competitive, as far as the use of capital invested is effective in transforming it to revenues and ultimately to adequate EBIT. The more prolific the transformation is, the more an efficient reflection of value creation it represents. It then satisfies the needs most of the stakeholders, who in return support the continuity of operation of the specific DMU as beneficial to society at large. 
We initially apply the constant return to scale DEA, the input oriented method using total assets (as the only input) and revenues and EBIT (as outputs), using the DEAfrontier softwear (Zhu), and we get the following results (Table 2):

Table 2. Input oriented CRS efficiency

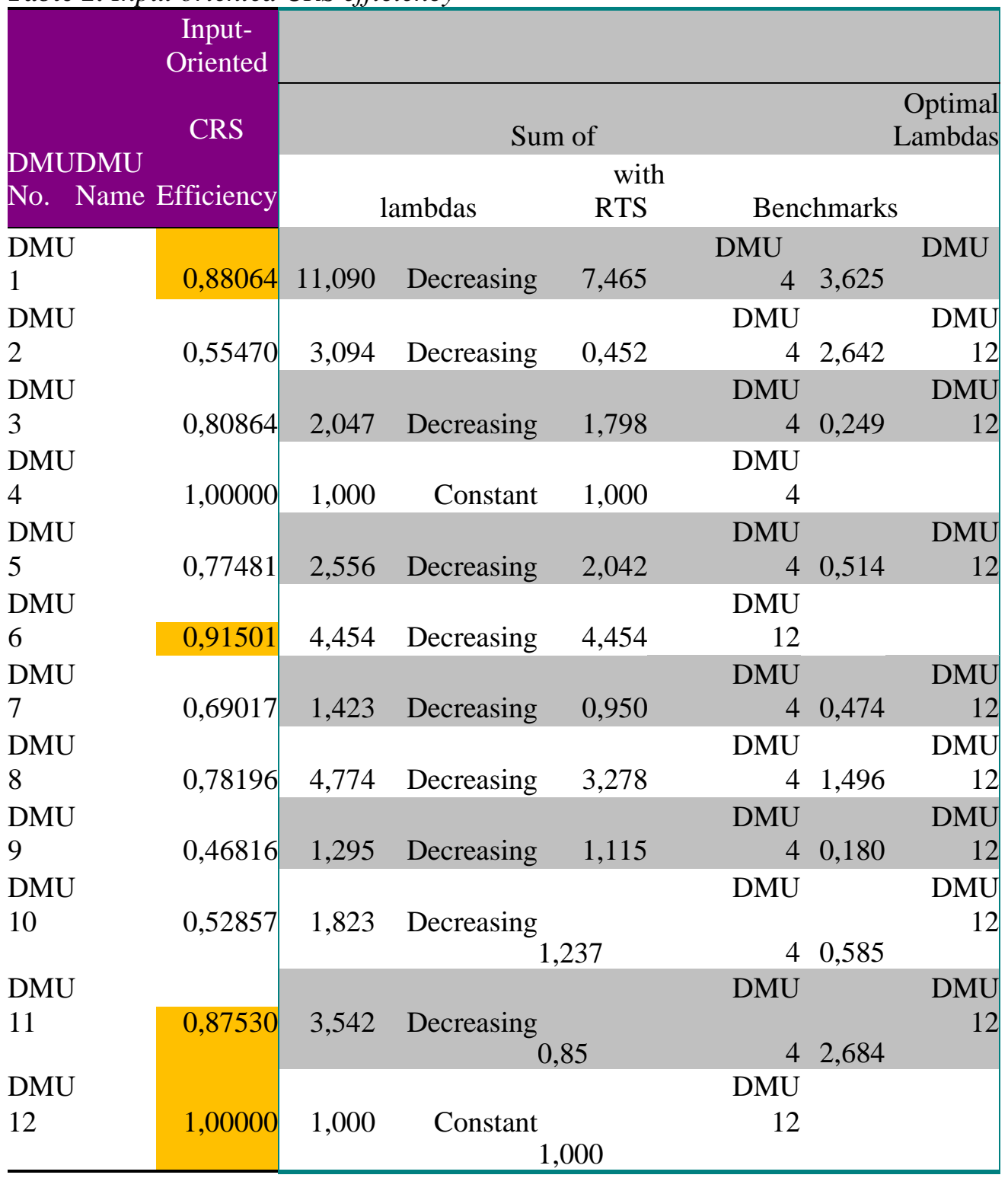

Source: Own calculations.

The average efficiency score of radial orientation of DMUs of the sample is equal to $77,3 \%$. It indicates that on the average inputs could be well reduced by $22,7 \%$ and 

338

the DMUs still achieve the same output. We also observe that DMUs No 4 and 12 exhibit efficiency score 1. Every other DMU is characterized as inefficient.

The sum of the CCR optimal lambda values can determine the RTS classification (Seiford, 1999). Since the sum of lambdas is greater than one, the DMUs are located inside in the inefficiency region. The ten inefficient DMUs operating under decreasing return to scale (any change in inputs is translated into a change in output at a lower rate).

The optimal lambdas show us that in order the remaining ten (10) inefficient DMUS to become efficient, must undergo a reduction in their input. The size of the reduction is reflected in the lambdas. The latter are variables related to the constraints that secure that the upper limit of the efficiency for each unit, doesn't surpass one (1). So, in case of the inefficient DMU1 to become efficient its input (total capital employed) must be decreased to $106.896,8$ ('000) euros, which is equal to efficiency score observed 0,88064 X 121.391,0 (the amount of the present use of total capital) or given the optimal lambdas ( and based on the two efficient DMUs 4 and 12) is equal to 7,465 X DMU4 +3,625 DMU12 = 7,465 X $10.517+3,625 \mathrm{X}$ $7.831,0=106.896,8$ ('000) euros.

An identical procedure is followed for the remaining nine (9) inefficient units. Their scale of operation (capital employed) must be decreased accordingly, if we want to transform them into efficient ones based on the efficient units DMU 4 and 12, that are located on the estimated efficient frontier, that its radial distance from the beginning of two axis (measuring the two outputs) is equal to $1(100 \%)$. Whatever is inside the region is considered inefficient (either the input has to reduced to achieve the same output or the output achieved must be increased using the same amount of input).

The existence of two efficient DMUs (No. 4 and 12) is evidently justified, since the outputs are two. Each of the two efficient DMUs excel in producing only one of the factors 1 st and 2nd columns (Table 3):

Table 3. Output / Input efficiency

\begin{tabular}{|c|c|c|}
\hline & Revenues / & EBIT/ \\
\hline & Total Assets & Total Assets \\
\hline DMU 1 & 0,196234 & 0,087774 \\
\hline DMU 2 & 0,123553 & 0,071738 \\
\hline DMU 3 & 0,180215 & 0,073071 \\
\hline DMU 4 & $\mathbf{0 , 2 2 2 8 7 7}$ & 0,08529 \\
\hline DMU 5 & 0,172667 & 0,072707 \\
\hline DMU 6 & 0,200782 & 0,127594 \\
\hline DMU 7 & 0,153792 & 0,068985 \\
\hline DMU 8 & 0,174248 & 0,077432 \\
\hline
\end{tabular}




\begin{tabular}{|c|c|c|}
\hline DMU 9 & 0,104333 & 0,042653 \\
\hline DMU 10 & 0,117783 & 0,052538 \\
\hline DMU 11 & 0,194978 & 0,107816 \\
\hline DMU 12 & 0,222705 & $\mathbf{0 , 1 3 9 4 4 6}$ \\
\hline
\end{tabular}

Source: Own calculations.

DMU 4 achieves an efficiency ratio of 0,222877 of revenues compared to capital, which is the highest among the 12 peer units of the sample. On the other hand, DMU 12 attains the highest percentage of EBIT to assets-capital (operating margin) among its peers which is equal to 0,139446 . The DMU 12 exhibits the most balanced performance with regards the input of total capital invested. Its conversion ratio of employed capital to EBIT (is the highest), as well as to revenues (the 2nd highest). DMU 4 though exhibits rather low performance in achieving EBIT margin to capital employed (Table 3). It is obvious that the DMU 12 gives the highest ratio of the two outputs to capital employed, which is equal to 0,362151. That is why DMU 12 is the most undisputable choice between the two efficient units as the optimal lambdas with benchmarks show (Table 2).

The two efficient DMUs can be prioritized further between them, if there is no parity among the two outputs. It can happen in case that the authority of the efficiency assessment, value them differently due to specific public policy orientation. If the energy self-suffiency concern is the overriding priority for the state, it may show preference in supporting DMU 4 which achieves the greater conversion ratio of capital-assets to revenues. It denotes that energy supply is maximized (given that prices of power are fixed by the state regulated long term contracts). If the main concern is to maximize the distributed financial results of operations among stakeholders or the degree of viability of the operation of units, then DMU No12 is preferred among the efficient ones. So the alleged weakness of DEA to prioritize among efficient units, can be resolved (at least partially), if the preferences of the involved parties in the assessment exercise, are somehow explicitly revealed.

\section{The Scale Effect}

Technical efficiency encompass the pure technical (operating on the existing production frontier) and scale efficiency. The scale of operation (the size of total assets invested) of the DMUs of our sample differs greatly, and it is prudent we also apply the Variable Return to Scale (VRS) model to capture the scale effect. Variable returns to scale (VRS) is a type of frontier appropriate to estimate efficiencies when a change in inputs leads to disproportionate change (increase or decrease) in the outputs. We discern increasing (a greater change) or decreasing (lower change) return to scale of the output, as a concomitant of the initial change in the input. Using Variable returns to scale (VRS) method for our sample of the twelve (12) DMUs, we get the following efficiency scores (Table 4): 
Data Envelopment Analysis (DEA) and Financial Ratios: A Pro-Stakeholders' View of

Performance Measurement for Sustainable Value Creation of the Wind Energy Sector 340

\begin{tabular}{|c|c|c|c|c|c|c|c|c|}
\hline \multirow[b]{3}{*}{$\begin{array}{c}D M \\
U \\
\text { No. }\end{array}$} & \multirow{2}{*}{\multicolumn{2}{|c|}{$\begin{array}{c}\text { Input- } \\
\text { Oriented } \\
\text { VRS }\end{array}$}} & & & & & & \\
\hline & & & $\begin{array}{r}\text { Optimal } \\
\text { Lambdas }\end{array}$ & & & & & \\
\hline & $\begin{array}{l}\text { DMU } \\
\text { Name }\end{array}$ & Efficiency & $\begin{array}{r}\text { with } \\
\text { Benchmarks }\end{array}$ & & & & & \\
\hline 1 & DMU 1 & 1,00000 & 1,000 & DMU 1 & & & & \\
\hline 2 & DMU 2 & 0,60568 & 0,014 & DMU 1 & 0,417 & DMU 4 & 0,569 & DMU 6 \\
\hline 3 & DMU 3 & 0,86896 & 0,107 & DMU 1 & 0,893 & DMU 4 & & \\
\hline 4 & DMU 4 & 1,00000 & 1,000 & DMU 4 & & & & \\
\hline 5 & DMU 5 & 0,84327 & 0,155 & DMU 1 & 0,845 & DMU 4 & & \\
\hline 6 & DMU 6 & 1,00000 & 1,000 & DMU 6 & & & & \\
\hline 7 & DMU 7 & 0,71507 & 0,009 & DMU 1 & 0,894 & DMU 4 & 0,097 & DMU 6 \\
\hline 8 & DMU 8 & 0,87287 & 0,360 & DMU 1 & 0,598 & DMU 4 & 0,042 & DMU 6 \\
\hline 9 & DMU 9 & 0,48233 & 0,022 & DMU 1 & 0,956 & DMU 4 & 0,022 & DMU 6 \\
\hline 10 & DMU 10 & 0,56098 & 0,052 & DMU 1 & 0,861 & DMU 4 & 0,087 & DMU 6 \\
\hline 11 & DMU 11 & 0,96339 & 0,071 & DMU 1 & 0,397 & DMU 4 & 0,533 & DMU 6 \\
\hline 12 & DMU 12 & 1,00000 & 1,000 & DMU 12 & & & & \\
\hline
\end{tabular}

Source: Own calculations.

We observe that efficiency score one, exhibit two additional DMUs the No 1 and 6, that are added to the No 4 and 12 fount under the CRS method. So one third of the total number of units are considered efficient under VRS method.

An activity is considered to have its most suitable productive scale size, when CCR and BCC efficiency scores coincide and are both equal to one (1). The Average efficiency score of DMU of the sample using the VRS method is equal to 82,6\%. It indicates that input could be reduced by $17,4 \%$ to achieve the same output.

Having estimated the efficiency score of DMUs under CRS and VRS we are able now to calculate the scale effect (SE) using the formula $S E=C R S / V R S$. Since CRS is always smaller than VRS score, the SE score lies between zero and one. When coincide in size, the DMU operates at the optimal productive scale "locally and globally" (Ederrer 2015). Otherwise the scale size should change.

Table 5. Scale efficiency

\begin{tabular}{|c|c|c|c|}
\hline & CRS & VRS & $\begin{array}{c}\text { Scale } \\
\text { Efficiency }\end{array}$ \\
\hline DMU 1 & 0,88064 & & 1 \\
\hline DMU 2 & 0,5547 & 0,60568 & $\mathbf{0 , 8 8 0 6 4 0 0 0}$ \\
\hline DMU 3 & 0,80864 & 0,86896 & $\mathbf{0 , 9 1 5 8 3 0 1 4}$ \\
\hline & & & $\mathbf{0 , 9 3 0 5 8 3 6 9}$ \\
\hline
\end{tabular}




\begin{tabular}{|c|c|c|c|}
\hline DMU 4 & & & \\
\hline DMU 5 & 0,77481 & 0,84327 & $\mathbf{0 , 9 1 8 8 1 6 0 4}$ \\
\hline DMU 6 & 0,91501 & & $\mathbf{0 , 9 1 5 0 1 0 0 0}$ \\
\hline DMU 7 & 0,69017 & 0,71507 & $\mathbf{0 , 9 6 5 1 7 8 2 3}$ \\
\hline DMU 8 & 0,78196 & 0,87287 & $\mathbf{0 , 8 9 5 8 4 9 3 2}$ \\
\hline DMU 9 & 0,46816 & 0,48233 & $\mathbf{0 , 9 7 0 6 2 1 7 7}$ \\
\hline DMU 10 & 0,52857 & 0,56098 & $\mathbf{0 , 9 4 2 2 2 6 1 0}$ \\
\hline DMU 11 & 0,8753 & 0,96339 & $\mathbf{0 , 9 0 8 5 6 2 4 7}$ \\
\hline DMU 12 & & & 1 \\
\hline
\end{tabular}

Source: Own calculations.

The average CRS technically efficiency was $77,3 \%$ and the corresponding VRS technically efficiency was $82,6 \%$, and therefore it may be said that DMUs are using resources close to optimal level. We observe that only $25 \%$ of DMUS are operating below a $60 \%$ score, with respect to CRS efficiency. It means that three fourths of units operating at levels close to their optical size and the VRS model doesn't improve considerably their efficiency scores obtained initially through the application of CRS model. So scale differences is not a core issue and the reliance on the CRS model in this case can be said is adequately justified.

\section{Performance Measurement and Profitability Ratios}

Revenues and operating income (EBIT), are used as outputs variables in DEA the of DMUs involved that are the constituent parts of the composite profitability ratio ROTA and are directly related to the main input variable, which is the total capital (assets) invested. Revenues represent the market share of the sector a DMU obtains through its operation. It represents effectiveness, since a desired outcome is achieved. EBIT on the other hand constitutes the distribution of the economic result of operation among shareholders (net income), other sources fund providers (banks, other creditors and suppliers) who are remunerated through interest charges and the state through tax collection entitled (since is responsible for providing supplementary infrastructures, operation licenses, environmental guidance and protection and other services etc). The duty of corporation to pay a reasonable share of taxes is considered paramount and a tangible proof of responsibility to the broader society, also recognized emphatically (in connection with protection of the wellbeing of labor, environment) by the business roundtable in 2019.

DEA can be a tool of assessing sustainable and inclusive growth. ROTA's building blocks contribute to managing a more balancing set of priorities, since takes into consideration some more of the stakeholders involved and not just shareholders, as does net profit margin and ROE financial ratios. A broader view of corporate governance represents paradigm shift, since "It asks managers to articulate the shared sense of the value they create, and what brings its core stakeholders together 

342

(Freeman et al., 2004). The stakeholders role and the long term implications of the resources allocation by corporations for the economy, society and the environment, in nowadays represents a movement that gains mounted support with the lapse of time (Davos, 2020). Towards that aim we examine the Return On Total Assets (ROTA) ratio, more closely.

Table 6. Return On Total Assets (Total Capital)

\section{EBIT}

DMU 1

DMU 2

DMU 3

DMU 4

DMU 5

DMU 6

DMU 7

DMU 8

DMU 9

DMU 10

DMU 11

DMU 12
$10.655,0$

$3.291,0$

$1.885,0$

897,0

2.393,0

4.864,0

$1.369,0$

$4.574,0$

$1.197,0$

$1.749,0$

$3.701,0$

1.092,0
Total Assets

121.391,0

$45.875,0$

$25.797,0$

$10.517,0$

3.2913,0

$3.8121,0$

$19.845,0$

$59.071,0$

28.064,0

$33.290,0$

$34.327,0$

$7.831,0$
ROTA= EBIT/Total

0,087774

0,071738

0,073071

0,085290

0,072707

0,127594

0,068985

0,077432

0,042653

0,052538

0,107816

0,139446

Source: Own calculations.

We calculate also a more narrow view of profitability of the Return on Equity that concerns primarily shareholders (Table 7).

Table 7. Return on Equity (ROE)

\section{Equity Capital}

\section{Net Income}

$6.804,0$

$1.743,0$

$1.362,0$

294,0

2.015,0

$3.151,0$

884,0

$1.862,0$

876,0

12.050
Return

On Equity

0,098152

0,149588

0,102948

0,095207

0,187233

0,149926

0,158253

0,069636

0,072697 


\begin{tabular}{lrrr} 
DMU10 & 15.350 & $1.132,0$ & 0,073746 \\
DMU 11 & 16.850 & $1.643,0$ & 0,097507 \\
DMU 12 & 5.633 & 802,0 & 0,142375 \\
\hline
\end{tabular}

Source: Own calculations.

Comparing DMUs on ROTA and ROE basis, we get different prioritization, as expected. Efficiency measurement scores based on DEA (CRS), ROTA and ROE ratios, constitute different ranking methods, that render diverse results presented in the following Table 8:

Table 8. Ranking of performance under DEA, ROTA, ROE

\begin{tabular}{lcrlrrr} 
& \multicolumn{1}{l}{ DEA- } & Ranking & ROTA & Ranking & ROE & Ranking \\
DMU 1 & 0,88064 & $\mathbf{3}$ & 0,087774 & $\mathbf{4}$ & 0,098152 & $\mathbf{7}$ \\
DMU 2 & 0,55470 & $\mathbf{9}$ & 0,071738 & $\mathbf{9}$ & 0,149588 & $\mathbf{4}$ \\
DMU 3 & 0,80864 & $\mathbf{5}$ & 0,073071 & $\mathbf{7}$ & 0,102948 & $\mathbf{6}$ \\
DMU 4 & 1,00000 & $\mathbf{1}$ & 0,085290 & $\mathbf{5}$ & 0,095207 & $\mathbf{9}$ \\
DMU 5 & 0,77481 & $\mathbf{7}$ & 0,072707 & $\mathbf{8}$ & 0,187233 & $\mathbf{1}$ \\
DMU 6 & 0,91501 & $\mathbf{2}$ & 0,127594 & $\mathbf{2}$ & 0,149926 & $\mathbf{3}$ \\
DMU 7 & 0,69017 & $\mathbf{8}$ & 0,068985 & $\mathbf{1 0}$ & 0,158253 & $\mathbf{2}$ \\
DMU 8 & 0,78196 & $\mathbf{6}$ & 0,077432 & $\mathbf{6}$ & 0,069636 & $\mathbf{1 2}$ \\
DMU 9 & 0,46816 & $\mathbf{1 1}$ & 0,042653 & $\mathbf{1 2}$ & 0,072697 & $\mathbf{1 1}$ \\
DMU 10 & 0,52857 & $\mathbf{1 0}$ & 0,052538 & $\mathbf{1 1}$ & 0,073746 & $\mathbf{1 0}$ \\
DMU 11 & 0,87530 & $\mathbf{4}$ & 0,107816 & $\mathbf{3}$ & 0,097507 & $\mathbf{8}$ \\
DMU 12 & 1,00000 & $\mathbf{1}$ & 0,139446 & $\mathbf{1}$ & 0,142375 & $\mathbf{5}$
\end{tabular}

Source: Own calculations.

The DEA based model assesses DMU 4 and 12 as efficient ones. Examining these units under the three different methods of estimating efficiency, we observe the following:

The DMU 4 that is efficient (ranks 1) under DEA, it is achieved mainly due to its highest relative efficient performance in translating capital employed into revenues (as shown in Table 3). The same unit ranks 5th under the ROTA criterion (EBIT/capital) and 9th under ROE ratio (Net income/Equity) among the 12th units. Its diverse scores are explained by the fact that the more the criteria pay attention to profitability (ROTA, a wider view) and especially the return to shareholders(narrow view) only, its performance decreases to the bottom of ranking. 
DMU12 which excels primarily due its performance in EBIT (profitability but of a wider perspective) is efficient under DEA and ROTA ratio and loses ground (ranks 5th) only under ROE which represents a narrow scope in profitability.

It is obvious that DEA using the two distinct constituent elements of ROI as separate items of output beaconed their individual importance. The ROTA outcome singled out the profitability (even the wider view of it) branch of the ratio. As we moved to ROE the return to shareholders only exacerbate the biased measurement that favors only one specific stakeholder at the expense of society as a whole that must promote inclusiveness as well, as the CEOs of the major US companies state (The Business Roundtable, 2019).

Given the previous observations we conclude that DEA measures performance in a more comprehensive way compared to financial ratios individually. It complements them in a meaningful and trustworthy manner, since its aspects of measurement are greater in number and more balanced, providing more confidence in quality of performance evaluation when the factors of assessment are diverse. So, we can attain a more balanced view of the decision- making units (Adler et al., 2002).

The method of DEA to work more effectively the numbers of DMUs examined and compared must be three times the sum variables used as inputs and outputs (Avrikan, 2014). A drawback of DEA is considered the fact that although is capable of performing a ranking for inefficient DMUs, at the same time efficient DMUs (in the case of more than one) cannot be ranked accordingly. In our case though we feel that this limitation is attenuated to some extent, since input and outputs are connected organically through the ROI ratio, that allows prioritization even among best performing units based on the priorities management, the competition forces in the vector and the position of the organization in it.

DEA has been criticized that by minimizing the amount of inputs it uses to produce a given level of output (or increases output for a given amount of inputs), it represents a pure technological optimization. It doesn't address the economic aspect, since it doesn't take in to consideration values. So, the output per se as a quantity doesn't guarantee value optimization, if it doesn't translate into value measures. Only the value that output commands, secure that is the right type of output (or combination of outputs in case of more than one) that market prefers. It is also possible other critics allege, to observe technical efficiency but due to different prices of inputs DMU forgoes allocative efficiency which embeds the cost of inputs. Thus the unit misses the profit maximization goal, which is achieved by incorporating that dimension. DEA, has also been blamed for not allowing for random error in the data, attributed mainly to measurement.

In our case all these alleged drawbacks, have been considerably mitigated due to three main factors, a) Inputs (total assets), as well as the two variables used as outputs (revenues and EBIT) are expressed in values, since represent data that are 
extracted from audited financial reports. So technical and allocative efficiency cannot diverge (due to any price differences), but coexist when variables express values. b) This type of operation (wind farming) produces only one output, its quality is fixed and is reflected in revenues. Finally, c) measurement errors are contained drastically, since data emanate from publicized financial statements which have been audited externally and revenues have been controlled by public electricity authority of Greece (DEH), which buys the output on behalf of the state. So, measurement errors of variable used in DEA, have been abated, if not eradicated completely. In addition the fixed assets dominated balance sheets of the wind farm sector, are not easily amenable to manipulation (Kourtis et al., 2007; 2019).

\section{Environmental, Social and Governance Issues (ESG)}

The procedure to use input and outputs variables related to ROTA, is more pertinent in nowadays due to the fact that "pressure on companies to pay attention to environmental, social, and governance (ESG) issues, continues to mount" (McKinsey, 2020). Performance and firm value have been found to be strengthened further in the case of management with appropriate ESG orientation. Stakeholders interests have been accommodated and extra financing through equity or debt is more readily attracted. ESG performance can be traced better under the DEA efficiency assessment model, that takes into accounts more inclusive measures of outputs. So, If we add to revenues (energy output due to fixed prices ) the associated carbon emission reduction (estimated $550 \mathrm{~g} \mathrm{CO} 2 \mathrm{eq} / \mathrm{kWh}$ ), the new permanent jobs created in remote and less developed areas, etc, then we can measure a whole range of benefits to stakeholders (such as shareholders, customers, employees, providers, banks, society, environmental agencies, health organizations, the state).

Advancing a strong ESG proposition through appropriate DEA measurement of sustainability and societal impact, we can help enhancing investment returns by allocating capital to more promising and more sustainable opportunities. It is true that "a strong ESG proposition can create value" since in the long run "shareholders and stakeholders do not compete in a zero-sum game" (McKinsey, 2019). DEA based benchmarking, can help wind farms become even more competitive, to reduce investment costs, as well as to improve further environmental and social performance.

In our case revenues indirectly reflect the electricity production of wind farms, since the prices are fixed by the state, which absorbs their supply of energy through a purchase obligation placed on the network operator at a predetermined price, in order to encourage investments in the sector of renewables. Thus through the amount of revenues we can measure the quantity of fossil reduction achieved and the mitigation of pollution attained, that boosts the quality of the environment and benefit the society as a whole. Wind generation is, therefore, effective at displacing fossil fueled generation and reducing emissions. 
An important factor affecting efficiency and is not included in our analysis is the existence of average favorable wind resource where DMUs are located. Wind speeds must well exceed a threshold of $6-7 \mathrm{~m} / \mathrm{s}$, in the islands and on mountain ridges in the mainland to allow viable wind farm operation. This an important input factor that is missing from the analysis. We assume that the decision to build electricity generation capacity in a specific area has taken into consideration that this factor exist anyway, so that wouldn't jeopardize its investment venture.

The impact to society ( besides the "significant decrease of harmful emissions") of an increase in renewable energy consumption by $1 \%$ has been found to boost GDP by $0.120 \%$, while contributing to the amelioration of annual per capita income of rural households by $0.444 \%$, compared to $0.368 \%$ for urban households (Rafique et al., 2018). Wind farms promote regional development and attenuate (to some degree) the disparity between center and periphery enhancing social inclusion.

\section{Conclusion}

Wind farm investors and management, as well as renewable energy policy makers, are interested in information regarding the efficiency in the use of investment funds in the sector. A sector that develops rapidly and is suitable in fulfilling social and environmental targets. DEA analysis is applied to examine how efficiently wind farms producing power using the main resources. Towards that aim we use data from financial statements as input and outputs. The data we have chosen are related to the constituent elements of the ROTA model. The latter contains the ratios of the operating (EBIT) margin and total capital turnover. To calculate those ratios (and ultimately ROTA), operating profits (EBIT), revenues and total assets are used. Total Assets represent the input and revenues as well as EBIT the output of the DEA model. The close ties among input and output variables of the DEA model, that have been long established in the financial analysis bibliography, renders them appropriate as a means to measure performance.

The DEA model used to estimate CRS and VRS efficiency. The scale efficiency was also calculated from the previous ones. DEA method using financial data was chosen to measure economic efficiency of wind farms. Errors in measurement applying financial data as input and outputs, were mitigated with the use of audited data.Based on results, benchmarks and good practices can be drawn from the records and the achievements of efficient units. The policymakers can develop strategies for the inefficient DMUs, to improve the utilization of resources and control the costs of operations, contributing to better asset allocation and wealth creation for more major stakeholders.

DEA alone though, cannot provide the appropriate prescription and secure the best course of action to cure suboptimal performance of the DMUs which are falling behind in efficiency. We found that there is a differentiation in ranking of ratio profitability measures (ROE and ROTA) and DEA efficiency results. DEA by using 
input and outputs data that are related meaningfully by being parts of composite ratios measuring performance, is provided with a well-grounded theoretical justification of the variables it chooses to examine. At the same time is equipped with well-established and tested reasoning, to suggest the appropriate steps for improving performance in the inefficient units. DEA is clearly aided through the use financial data as inputs and outputs.

The fact that these are forming financial ratios of performance, help DEA to explain the results and prescribe strategies of improving efficiency in a more orderly fashion revealing cause and effect relationships. DEA allows composite ratios (ROE, ROA, ROTA, ROCE etc) that are products of more than one individual ratio, to delineate more clearly the impact of each one of the building blocks on the overall performance.

Using values (financial data) as inputs and outputs, we take care also the aspect of the allocative efficiency that takes in to consideration prices also (besides quantities). At the same time by utilizing audited data extracted from published financial reports, we mitigate the problem of measurement of the variables used as inputs and outputs, that plague DEA. The fact also, that the sector is dominated by fixed assets and revenues emanate from long term contracts with the state, gives not enough leeway to management for data manipulation (Kourtis et al., 2017; 2019) that is performed mainly through current assets (receivables and inventories).

The sector of renewable energy through its inherent favorable characteristics, is almost ideally conducive to the new ambitious direction of corporate governance. ROTE building blocks secure economic efficiency on one hand and at the same time facilitate the management of a more balanced and all-inclusive set of priorities for the economic entities.

DEA analysis can be extended by incorporating and other output variables (job creation numbers, environmental pollution etc). It can accommodate any stakeholders' wellbeing concerns for the DMU's entire ecosystem, that is enshrined in the new Statement on the Purpose of a Corporation "to create benefits to all of its stakeholders" promulgated fairly recently by the Business Round Table. The corporate governance policy prescribed in the new economic and social environment, states: "As business leaders representing every sector of the American economy, we are committed to upholding the highest standards of corporate governance. These standards not only promote integrity and accountability for investors, they are paramount to advancing the long-term economic interests of America's workers, families and communities “ (Business Round Table, 2019).

This message was verified and embraced in Davos 2020 under the theme of "stakeholders for a cohesive and sustainable world", that gives more emphasis in the protection of the environment by corporations. This approach despite of any short term trade offs, in the long run it is believed to create more prosperity for all 
parties involved. The fact that small investments in wind farms do not fall behind in efficiency, is a sign that its social impact can be increased further by encouraging such a scale investments, especially in remote areas, where development and employment problems are exacerbated by the existing policies.

\section{References:}

Adler, N., Friedman, L., Sinuany-Stern, Z. 2002. Review of ranking methods in the data envelopment analysis context. European Journal of Operational Research, 140, 249-265.

Altman, E.I. 1968. Financial ratios, discriminant analysis and the prediction of corporate bankruptcy. The Journal of Finance, Vol. 4, 589-609.

Avkiran, N.K. 2011. Association of DEA super-efficiency estimates with financial ratios: Investigating the case for Chinese banks. MMEGA, 39, 323-334.

Avkiran, N.K. 2014. A tutorial on using dynamic network DEA to benchmark organizational performance. The University of Queensland, Brisbane, Australia.

Banker, R.D., Charnes, A, Cooper, W.W. 1984. Some models for estimating technical and scale inefficiencies in data envelopment analysis. Management Science, 30, 10781092.

Batchimeg, B. 2017. Financial Performance Determinants of Organizations: The Case of Mongolian Companies. Journal of Competitiveness, 9(3), 22-33.

Bernstein, L.A. 1988. Financial statement analysis, theory, application, and interpretation. Journal of Accounting Research, Vol. 3, 61-80.

Brooking Institution. 2020. Available at: https://www.brookings.edu/blog/futuredevelopment/2020/01/21/stakeholder-capitalism-arrives-at-davos/.

Business Roundtable. 2019. Available at: https://www.businessroundtable.org/policyperspectives/energy-environment.

Coelli, T.J. 1995. Recent Developments in Frontier Modelling and Efficiency Measurement. Australian Journal of Agricultural Economics, 39, 219-245.

Charnes, A., Cooper, W.W., Rhodes, E. 1978. Measuring the efficiency of decision making units. European Journal of Operational Research, 2, 429-444.

Cooper, W.W., Seiford, L.M., Zhu, J. 2011. Data Envelopment Analysis: History, Models, and Interpretations. Springer.

Courtis, P. 2003. Du Pont ratio: A comprehensive measure of business performance. European Research Studies Journal, 6(1-2), 21-34.

Courtis, P., Mylonakis, J. 2008. A holistic approach of assessing and improving competitiveness in tourism: the case of Ionian Islands (Greece). Problems and Perspectives in Management, 6(3).

Curtis, P., Thalassinos, E.J. 2005. Equity fund raising and "creative" accounting practices: Indications from Athens Stock Exchange for the 1999-2000 period. European Research Studies Journal, 8(1-2), 127-135.

Curtis, P., Kokotos, D. 2008. A Decision Tree Application in Tourism based Regional Economic Development. TOURISMOS, 4, 169-178.

Damodaran, A. 2020. Fundamental Growth in EBIT by Sector (US). Available at: http://www.stern.nyu.edu/adamodar/New_Home_Page/data.html

Ederer, N. 2015. Evaluating capital and operating cost efficiency of offshore wind farms: A DEA approach. Renewable and Sustainable Energy Reviews, 42, 1034-1046.

Ernst Young. 2019. Available at: https://www.ey.com/en_uk/power-utilities/renewable- 
energy-country-attractiveness-index

Farrell, M.J. 1957. The Measurement of Productive Efficiency. Journal of the Royal Statistical Society, 120, 253-290.

Freeman, R.E., Wicks, A.C., Parmar, B.L. 2004. Stakeholder theory: The corporate objective revisited. Organization Science, 15(3), 364-369.

Fried, H.O., Lovell, L.C.A., Schmidt, S.S. (eds). 2008. The Measurement of Productive Efficiency and Productivity Growth. Oxford University Press, 1-106.

IEEF. 2018. The American wind-energy horse is outofthe barn. Available at: https://ieefa.org/ieefa-update-the-american-wind-energy-horse-isout-of-the-barn/

Kourtis, E., Kourtis, G., Curtis, P. 2019. An Integrated Financial Ratio Analysis as a Navigation Compass through the Fraudulent Reporting Conundrum: A Case Study. International Journal of Finance, Insurance and Risk Management, 9(1-2), 3-20.

Kourtis, G., Kourtis, E., Kourtis M., Curtis, P. 2017. Fundamental Analysis, Stock Returns and High B/M Companies. International Journal of Economics and Business Administration, 5(4), 3-18.

Lin, W.C., Liu, C.F., Chu, C.W. 2009a. Financial Statement Analysis and Activity-Based Costing Analysis for Shipping Industry: A Data Envelopment Analysis Approach. Proceedings of the Eastern Asia Society for Transportation Studies, Vol. 7.

Lin, W.C., Liu, C.F., Chu, C.W. 2009b. Performane efficiency evaluation of the Twiwan's shipping industry: An application of data envelopment analysis. Proceedings of the Eastern Asia Society for Transportation Studies, 5, 467-476.

McKinsey. 2019. Five ways that ESG creates value. November issue.

McKinsey. 2020. The ESG premium: New perspectives on value and performance. February issue. Available at:

https://www.mckinsey.com/ /media/McKinsey/Business\%20Functions/Sustaina bility/Our\%20Insights/The\%20ESG\%20premium\%20New\%20perspectives\%20 on\%20value\%20and\%20performance/The-ESG-premium-New-perspectives-onvalue-and-performance.ashx.

Malhotra, D.K., Malhotra, R. 2008. Financial statement analysis using using data envelopment analysis. Philadelphia University.

Rafique, M.M., Rehman, S., Alam, M.M., Alhems, L.M. 2018. Feasibility of a 100 MW Installed Capacity Wind Farm for Different Climatic Conditions. Energies, 11, 21-47. Available at: www.mdpi.com/journal/energies.

Seiford, L.M, Zhu, J. 1999. An investigation of returns to scale in data envelopment analysis. Omega, Int. J. Mgmt. Sci. 27, 1-11.

Smith, P. 1990. Data Envelopment Analysis Applied to Financial Statements. OMEGA International Journal of Management Science, 18(2), 131-138.

Thomson, R.C., Harrison, G.P. 2015. Life Cycle Costs and Carbon Emissions of Offshore Wind Power. University of Edinburgh, 1-67. Available at: https://www.climatexchange.org.uk/media/1461/main_report_life_cycle_costs_a nd_carbon_emissions_of_offshore_wind_power.pdf.

U.S Energy Information Administration. 2020. Levelized Cost and Levelized Avoided Cost of New Generation Resources in the Annual Energy Outlook 2020. Available at: https://www.eia.gov/outlooks/aeo/pdf/electricity_generation.pdf.

Vagiona, D.G., Kamilakis, M. 2018. Sustainable site selection for offshore wind farms in the South Aegean-Greece. Sustainability, 10, 749.

Weersink, A., Calum, G.T., Abdulahi, G. 1990. Decomposition Measures of Technical 
Efficiency for Ontario Dairy Farms. Canadian Journal of Agricultural Economics, $38,439-456$.

Wind-energy-org. 2019. Available at: https://www.wind-energy-the-facts.org/the-cost-ofenergy-generated-by-wind-power.html.

Windeurope.org. 2020. https://windeurope.org/about-wind/wind-energy-today/.

World Economic Forum. 2020. Davos Manifesto 2019 Stakeholder capitalism. Available at: https://www.businessroundtable.org/business-roundtable-redefines-the-purposeof-a-corporation-to-promote-an-economy-that-serves-all-americans.

World Street Journal. 2020. Wind, Solar Farms Are Seen as Havens in Coronavirus Storm. Available at: https://www.wsj.com/articles/wind-solar-farms-are-seen-as-havensin- coronavirus-storm- 11585656003.

Zhou, H., Yang, Y., Chen, Y., Zhu, J. 2018. Data envelopment analysis application in sustainability: the origins, development and future directions. European Journal of Operational Research, 264, 1-16.

Zhu, J. 2013. Available at: http://www.deafrontier.net/index.html. 